BULLETIN Bulletin hispanique

HISPANIQUE Université Michel de Montaigne Bordeaux

122-1 $\mid 2020$

Variations donjuanesques

\title{
Ramón Gómez de la Serna, Greguerías. Brouhahas
}

Paris, Classiques Garnier, 2018

Jacques Issorel

\section{CpenEdition}

Journals

Édition électronique

URL : http://journals.openedition.org/bulletinhispanique/11033

DOI : 10.4000/bulletinhispanique. 11033

ISSN : 1775-3821

Éditeur

Presses universitaires de Bordeaux

Édition imprimée

Date de publication : 18 juin 2020

Pagination : 374-376

ISBN : 979-10-300-0592-9

ISSN : 0007-4640

Référence électronique

Jacques Issorel, «Ramón Gómez de la Serna, Greguerías. Brouhahas », Bulletin hispanique [En ligne], 122-1 | 2020, mis en ligne le 18 juin 2020, consulté le 19 janvier 2021. URL : http://

journals.openedition.org/bulletinhispanique/11033 ; DOI : https://doi.org/10.4000/bulletinhispanique. 11033

Ce document a été généré automatiquement le 19 janvier 2021.

Tous droits réservés 


\section{Ramón Gómez de la Serna, Greguerías. Brouhahas}

Paris, Classiques Garnier, 2018

Jacques Issorel

\section{RÉFÉRENCE}

Ramón Gómez de la Serna, Greguerías. Brouhahas, traduction et édition critique par Laurie-Anne LAGET. - Paris : Classiques Garnier, 2018, 550 p. (Littératures du Monde, 31). ISBN : 978-2-406-08388-7 - ISSN : 2115-5674.

1 Ramón Gómez de la Serna (Madrid, 1881 - Buenos Aires, 1963) partage avec Juan Ramón Jiménez et Federico García Lorca le privilège, unique dans les lettres espagnoles, d'être fréquemment désigné par son seul prénom. Il doit ce traitement amical et familier à l'admiration universelle suscitée par le gigantisme de son œuvre (ses O.C. comptent 20 volumes auxquels il faut ajouter son «monumental travail journalistique», p. 11) et, plus encore, par les 20.000 (30.000?) greguerías, pour partie recueillies dans Total de greguerías (1962) et, pour partie, publiées dans la presse entre 1910 et 1963. C'est donc à un Everest littéraire que s'est attaquée Laurie-Anne Laget en réunissant dans ce fort volume quelque 1.700 greguerías, en les traduisant, en fournissant au lecteur dans une substantielle préface (p.9-53) les "éléments de contexte indispensables sur la formation littéraire » de l'auteur et en expliquant, dans une prose claire, élégante, précise, les « ressorts de l'esthétique ramonienne » (p. 13).

2 Elle insiste d'abord sur la singularité du personnage que fut Ramón, à la fois, journaliste, écrivain, mais aussi conférencier atypique, «juché sur un éléphant ou perché sur un trapèze » (p. 14), véritable vedette de music-hall, dont le public applaudit les toujours nouvelles facéties autant que le contenu de son discours. Lui-même déclare volontiers dans le Prólogo de Total de greguerías (p. 56-163), reproduit après la préface : "Gracias a las Greguerías he vivido, he conferenciado, he viajado, he tenido contraseña universal» (p. 58). Quand Valery Larbaud le découvre, au début des années 20, il a 
trente ans, s'est déjà essayé à tous les genres littéraires - hormis la poésie en vers - et a publié pas moins de 38 volumes et un nombre faramineux d'articles de presse (plus de 225 par an!). Cependant, plus que ses articles journalistiques, plus que ses romans, ses essais, ses pièces de théâtre, ce sont les greguerías qui ont rendu leur auteur célèbre jusqu'à faire de lui, dès le début des années 20 , « un véritable phénomène médiatique » (p. 18).

3 Ramón revisite l'art de la tertulia au café de Pombo, sa "Sagrada Cripta », fait de son bureau du Torreón (calle de Velázquez) un «monde magique " d'images et d'objets hétéroclites (p. 22) et se révèle un as de la communication, sans jamais perdre de vue son objectif : faire "découvrir des choses nouvelles» au public, l'inviter à "changer son regard sur le monde, à le repenser par le détour d'une lecture figurée » (p. 22). Et c'est bien à cela que visent les greguerías dont Laurie-Anne Laget analyse magistralement « l'insaisissable formule » dans les pages 28-36 de la préface. À la fois, ou tour à tour, bref poème («Raja de sandía: luna de sangre», p. 340), énigme, proverbe, calembour, définition («Turismo: el arte de estar huyendo», p. 434), bon mot, micro-récit, la greguería, "genre polymorphe, [...] échappe à toute tentative de définition univoque» (p. 29). D'ailleurs, Ramón lui-même attendit d'en avoir écrit plusieurs milliers avant de proposer en 1943, soit trente ans après la première, l'équation : « Humorismo + metáfora = greguería ».

4 Malgré son aspect définitif, cette formule ne l'a pourtant pas satisfait, puisque dans le long Prólogo, daté de 1962, cité plus haut, il revient inlassablement sur cette même question, ouvre une infinité de pistes avec des phrases commençant par « La greguería es... » ou " No es la greguería... », puis retrouve d'illustres pionniers tels qu'Euripide, Góngora, Shakespeare, Verlaine, Saint-Pol-Roux et bien d'autres, avant de rappeler que la greguería a été imitée, copiée, plagiée, et a suscité des émules en Espagne et en Amérique latine, tenant ainsi en haleine le lecteur jusqu'au point final, sans jamais lui offrir LA définition tant attendue !

Laurie-Anne Laget compense largement cette frustration quand elle écrit qu'avec la greguería Ramón nous propose «une lecture figurée du monde, au travers d'associations d'images, qu'il constitue en une réalité poétique, inédite, une réalité plurielle invitant à la rêverie » (p. 33). Elle ne s'en tient pourtant pas là et poursuit son analyse de la greguería dans la dernière partie de sa préface, intitulée : "Traduire les greguerías. Une parole poétique détournée et remotivée » (p. 36-51). Traduire d'abord le mot lui-même. Après avoir souligné qu'il ne s'agit nullement d'un néologisme, puisque greguería figure dans le Diccionario de Autoridades (1734) avec le sens de "Confusión de voces, que no se perciben clara y distintamente» (p.33), elle opte pour Brouhaha, qui présente le double avantage d'être proche du sens espagnol et de suggérer le côté surprenant, étrange, voire déroutant au premier abord des greguerías. Valery Larbaud avait opté pour « criailleries » (p. 11).

Le travail de la traductrice a concerné, d'une part, le prologue de Ramón, d'autre part, les greguerías par elle choisies. Bien qu'apparemment «facile», le prologue présente constamment des difficultés de transposition de l'espagnol vers le français. LaurieAnne Laget les surmonte toutes avec une remarquable aisance. Quant aux greguerías, rares sont celles capables d'admettre une traduction littérale. Pour restituer en français leur ton vif, humoristique, poétique, la traductrice les refaçonne, les remanie, souvent les recrée, avec une telle délicatesse qu'elles rendent dans leur forme française le son 
juste qu'elles possédaient en espagnol (« La “ñ" es la “n” con bigote » : « Le “ê”, c'est un "e" moustachu », p. 350).

7 Deux annexes («Nueva explicación de las Greguerías / Nouvelle explication des Brouhahas ", texte rédigé par Ramón avant sa mort, et "Greguerías inéditas. 1962 / Brouhahas inédits. $1962 »)$, une bibliographie et un index onomastique complètent cette belle et première édition critique bilingue de l'œuvre la plus brillante d'un écrivain hors norme, qui, selon Melchor Fernández Almagro, constitua une génération à lui seul (p. 14).

\section{AUTEURS}

JACQUES ISSOREL

Université de Perpignan 